\title{
Colorectal anastomosis dehiscence: a call for more detailed morphological classification
}

\author{
Alexander Ferko ${ }^{1}$, Jan Rejholoc ${ }^{2}$, Matej Škrovina ${ }^{3}$, Ilja Tachecí ${ }^{4}$, Igor Sirák ${ }^{5}$ \\ ${ }^{1}$ Department of Surgery and Transplant Center, Comenius University, Jessenius Medical Faculty Martin and University Hospital Martin, \\ Bratislava, Slovak Republic \\ ${ }^{2}$ Department of General Surgery, Regional Health Ltd., Hospital Děčín, Děčín, Czech Republic \\ ${ }^{3}$ Department of Surgery, Hospital Nový Jičin, Nový Jičin, Czech Republic \\ ${ }^{4} 2^{\text {nd }}$ Department of Internal Medicine, Charles University, Medical Faculty Hradec Králové, University Hospital Hradec Králové, Hradec \\ Králové, Czech Republic \\ ${ }^{5}$ Department of Oncology and Radiotherapy, Charles University, Medical Faculty Hradec Králové, University Hospital, Hradec Králové, \\ Czech Republic
}

Videosurgery Miniinv

DOI: https://doi.org/10.5114/wiitm.2020.97367

\begin{abstract}
Introduction: A proactive approach is recommended in colorectal anastomosis leak treatment, and early diagnosis is very important. Early postoperative endoscopy would allow rapid diagnosis of anastomotic pathologies and consequent prompt intervention according to anastomotic disruption morphology.

Aim: To evaluate the effectiveness of close endoscopic follow-up of all patients (including asymptomatic ones) in improving diagnosis of acute leak (AL) and reducing its complications.

Material and methods: This study included 124 patients who had undergone rectum resection for rectal cancer with stapled anastomosis. Endoscopy was performed between the $7^{\text {th }}$ and $10^{\text {th }}$ postoperative day and 1 month postoperatively. For defect morphology assessment, a classification system was created based on four levels of severity. Photographic findings were evaluated by an independent, experienced gastroenterologist.

Results: Postoperative endoscopy revealed 28 (22.6\%) patients with acute leakage. Initial endoscopy confirmed AL in 18 patients. Six (31.6\%) patients were asymptomatic and 13 (68.4\%) were symptomatic. The second endoscopy revealed another $9(32.1 \%)$ leaks (4 (44.5\%) asymptomatic and 5 (55.5\%) symptomatic). Sixteen (57.1\%) patients had grade A leakages, 7 (25.0\%) had grade B leakages, and 5 (17.9\%) had grade Cleakages. Furthermore, 22 of 27 (81\%) defects were located posterior and posterior-laterally. Fifteen (55.5\%) defects were smaller than $1 / 3$ the circumference, 7 (25.9\%) affected 1/3-1/2 of the circumference, and 5 (18.5\%) affected more than 1/2 of the circumference. Conclusions: Incorporation of early endoscopy in postoperative management allows rapid diagnosis of $A L$ and allows faster intervention, even in leaks that are clinically silent.
\end{abstract}

Key words: rectal cancer, anastomotic leak, low anterior resection.

\section{Introduction}

The non-healing of anastomosis after rectal resection is a serious complication that may not be predicted by even the most experienced surgeon. The incidence of anastomotic leakage $(A L)$ of the rectum, in contrast to leakage of the colon, is reported to range between $1 \%$ and $28 \%$ [1]. This wide range of

\section{Address for correspondence}

Prof. Alexander Ferko MD, PhD, Department of Surgery and Transplant Center, Comenius University, Jessenius Medical Faculty Martin and University Hospital Martin, Bratislava, Slovak Republic, e-mail: a.ferko@seznam.cz 
findings is due to several factors. The primary cause is most likely acute leakage classification inconsistencies [2, 3]. Another aspect that may distort the objective reality of leakage incidence is non-detection of clinically silent leaks. Protective stomata certainly contribute to the suppression of symptoms. Leaks that are "hidden" behind the ileostomy are often asymptomatic or manifest very discreetly in the early postoperative period, and it is well known that institutions have different approaches to colon diversion in rectal cancer surgery. In asymptomatic patients, examination for leakage is not generally performed; consequently, those patients are rarely reported [4] The low diagnostic power of the currently used diagnostic methods, as an irrigography or computed tomography (CT) scan, may be another cause of leak non-detection [5-7].

Not only leaks, but also septic consequences negatively influence patient postoperative course. Anastomotic dehiscence probably has negative impacts on oncological results, which has been reported in a subgroup of symptomatic patients [1]. Leaks probably have a negative impact on functional outcomes and the patient's quality of life, but detailed research on these factors is lacking.

Currently, a proactive approach is recommended in acute leak treatment and thus early diagnosis is very important [7]. Changes in C-reactive protein (CRP) may be a useful tool reflecting acute infection during an active search for dehiscence [7]. Our initial experience has shown that endoscopy allows for the rapid diagnosis of anastomotic pathologies and consequent prompt intervention according to anastomotic disruption morphology.

\section{Aim}

We aimed to evaluate the effectiveness of close endoscopic follow-up of all patients (including asymptomatic ones) in improving diagnosis of $A L$ and reducing its complications.

\section{Material and methods}

This study was conducted between 1 July 2015 and 1 July 2016 at three hospitals. This study was approved by the ethics committee of our institution and was conducted in accordance with the Declaration of Helsinki. All patients provided written informed consent. The study included 124 consecutive patients older than 18 years who underwent resection of the rectum and stapled anastomosis for rectal cancer located within $15 \mathrm{~cm}$ of the anus. All patients had undergone standard preoperative diagnostic evaluation, e.g. colonoscopy, endorectal sonography, or pelvic magnetic resonance imaging. The nutritional status of the patients was evaluated preoperatively and the patients at risk underwent oral nutritional preparation. The enhanced recovery after surgery (ERAS) protocol was used perioperatively. If patients had undergone chemoradiotherapy (CHRT), restaging was performed within 6 weeks of CHRT completion, and surgery was performed 10 weeks after CHRT completion. The standard CHRT regimen involved irradiation with $45 \mathrm{~Gy}$ in 25 fractions to the pelvic area, the rectum, and the pararectal, presacral, and internal iliac lymph nodes. A supplementary boost dose of radiation was applied to the tumour itself (5.4 Gy in 3 fractions) for a total dose of 50.4 Gy. Radiotherapy was potentiated by chemotherapy with continuous 5 -fluorouracil infusion at a dose of $200 \mathrm{mg} / \mathrm{m}^{2} / 24 \mathrm{~h}$ for the entire duration of radiotherapy. CHRT was indicated in all cT3/cT4 or $\mathrm{N}+$ tumours.

\section{Surgical technique}

Surgical procedures were performed by experienced surgeons who perform more than 30 rectal resections per year and have sufficient expertise in minimally invasive surgery. Most of the operations were performed mini-invasively. Seventy-two (58\%) of the operations were laparoscopic, 42 (34\%) were robotically assisted, and 10 (8\%) were open. Total mesorectal excision (TME) was performed in 94 (75.8\%) patients, while partial mesorectal excision was performed in the remaining 30 (24.2\%) patients. Dissection was performed using a medial to lateral approach, and the inferior mesenteric artery was not always ligated; additionally, splenic flexure mobilization was not always performed. The type of anastomosis performed was based on the surgeon's preference. Prior to anastomosis, the rectal stump was lavaged with betadine (Egis Pharmaceuticals, PLS, Budapest, Hungary) and water at a concentration ratio of $1: 10$. The air leak test and anastomosis inspection were performed at the end of the procedure. Diverting ileostomy was performed selectively in male patients after neoadjuvant CHRT who underwent total mesorectal excision or in patients with a positive air leak test. Resected specimens were 
parametrically evaluated using positive circumferential resection margin ( $\mathrm{pCRM}$ ) and excision quality.

\section{Follow-up, endoscopic examination, and leakage diagnosis}

After rectal resection, patients underwent endoscopic examination. The first endoscopic examination was performed a day before the patient was discharged, and the second was scheduled on or near the $30^{\text {th }}$ postoperative day and was conducted as an outpatient endoscopic examination. If the patient experienced symptoms earlier, endoscopy was performed immediately. The second endoscopy was not performed in patients who lost their anastomosis because of leakage and reoperation. The examination was performed gently, only to the level of anastomosiswith minimal insufflation, in patients without protective ileostomy after short-term prepa- ration with an enema (Yal Gel, Trommsdorf $\mathrm{GmbH}$ and Co. KG, Arzneimittel, Germany) along with photographic documentation. A pelvic CT scan was performed in selected patients based on presence of symptoms and endoscopic findings. Leak location was assessed using a clock dial, by measuring the clockwise from-to distance. In case of clear circumferential orientation absence, a level of lavage fluid was created. For the purpose of the defect morphology assessment, the following classification was created (Photos 1, 2):

1) defect $<12 \mathrm{~mm}$, impenetrable with an endoscope, cavity \pm ;

2) defect $>12 \mathrm{~mm}$, cavity \pm ;

3) defect $<1 / 2$ the circumference of anastomosis, cavity \pm ;

4) defect $>1 / 2$ the circumference of anastomosis, cavity \pm .


C

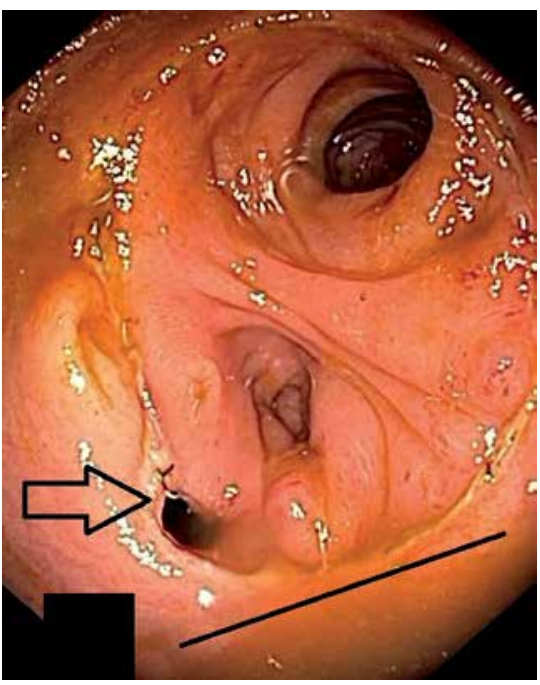

Photo 1. Patients with clinically silent leak. A - Posterior defect in anastomosis $<12 \mathrm{~mm}$ (black arrow), endoscopy 8 days after surgery. B - Patient with asymptomatic posterior-lateral defect (black arrow), released stapler clamps (black full arrow). Endoscopy performed 28 days after surgery. C - Patient with side-to-end anastomosis, small defect at number 7 (black arrow), fluid level indicates posterior wall (black line). Endoscopy performed 30 days after surgery 
A
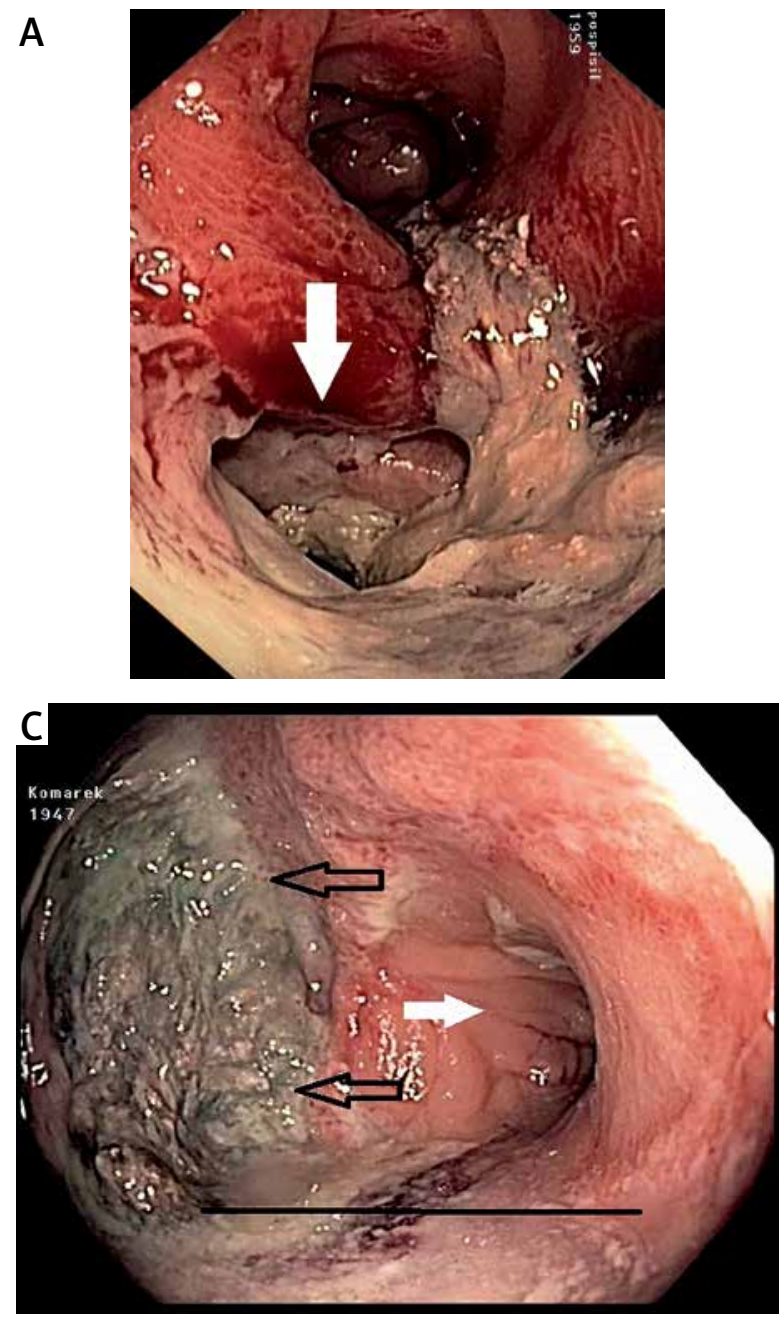

All 4 categories would be associated with or without colon ischaemia and/or colon retraction.

To assess the changes between the first endoscopy and the second at day 30, the endoscopic findings were evaluated and classified as follows:

1) no leakage;

2) with leakage on first endoscopy, communication is healed;

3) with original leakage, anastomotic defect progression;

4) newly diagnosed leakage.

\section{Post-study endoscopic photo documentation evaluation}

At the end of the study, all anastomosis findings were evaluated. Photographic findings were evaluated by an independent and experienced gastroenterologist. Patient data were blinded so the evaluator

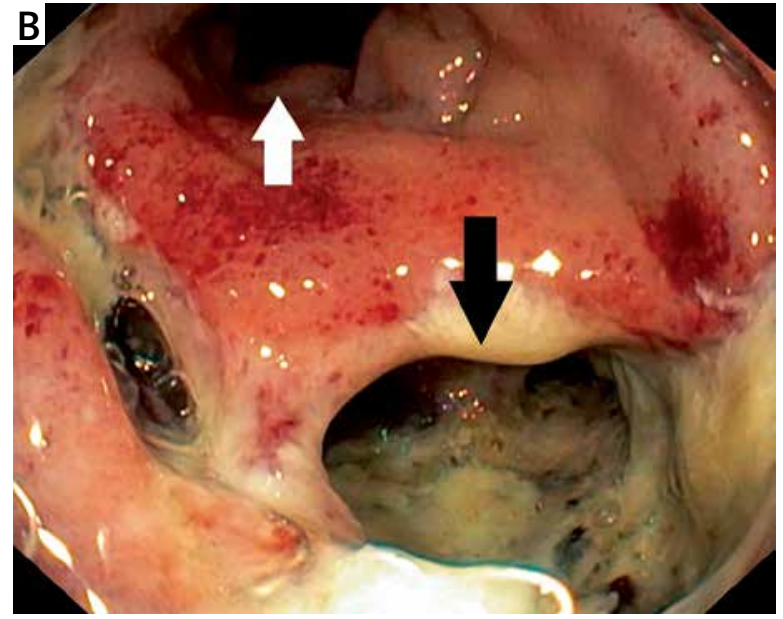

Photo 2. Anastomotic defects $>12 \mathrm{~mm}$, symptomatic patients. A - Posterior defect, necrotic tissue (white arrow). Endoscopy 5 days after surgery. B - Large anastomotic posterior defect (black arrow), with pus and necrosis, colon (white arrow). Endoscopy 6 days after surgery. C - Extensive postero-lateral defect $>1 / 2$ of circumference with necrotic cavity (white arrow), colon (black arrow). Endoscopy 20 days after surgery. All cases treated by vacuum therapy (Endosponge, B. Braun, Germany)

did not know the details of patient treatment. To assess endoscopic findings, the characteristics of standard well-healed anastomoses were established. All deviations from this finding were classified. For these purposes, this endoscopic pathomorphological classification was created (Photos 3-6):

1) no pathological finding

2) anastomosis defect $<12 \mathrm{~mm}$;

3) anastomosis defect $>12$ with cavity;

4) anastomosis inflammation - redness or erosion of the mucosa extending beyond the anastomosis edge;

5) anastomosis ulcer - fibrin clot that does not match the width of the sutured tissue;

6) non-stenotic fibrosis - clear signs of tissue retraction;

7) inflammatory polyps;

8) stenosis. 


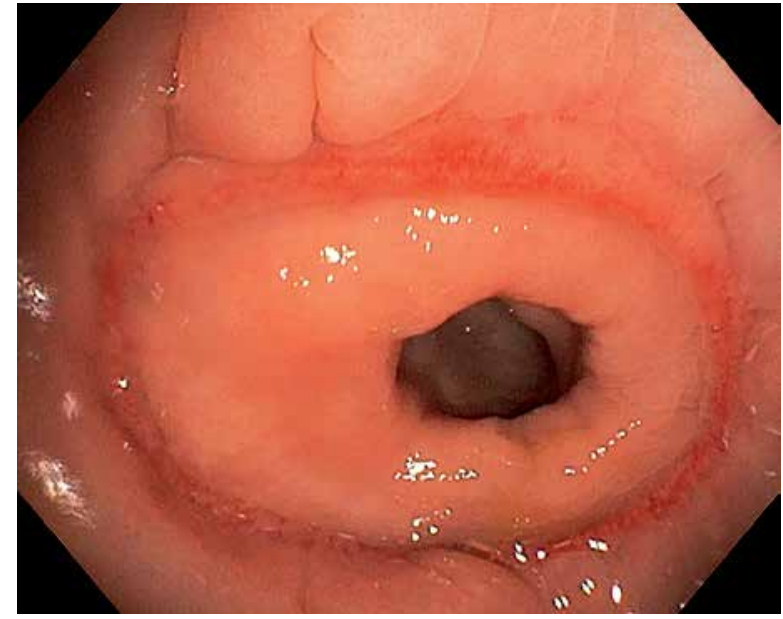

Photo 3. Findings defined as reference standard for further assessment. Patient after TME, anastomosis at $4 \mathrm{~cm}$ from anal verge. Staples are well healed, anastomosis is without stenosis, and the oral section of the colon has achieved anastomosis without tension. Endoscopy performed 30 days after surgery



Photo 5. Fibrosis, released clamps (black arrow) and inflammatory polyps (white arrow). Endoscopy performed 30 days after surgery

Endoscopic signs of possible causes of the lack of anastomosis healing included intestinal ischemia, anastomosis tension, and released stapler clamps.

\section{Data collection and evaluation}

Data were collected prospectively and stored anonymously in the registry after assigning patient identification numbers. In addition to the initial and repeat staging of the tumour, data regarding the type of procedure, type of anastomosis, the number of sta-

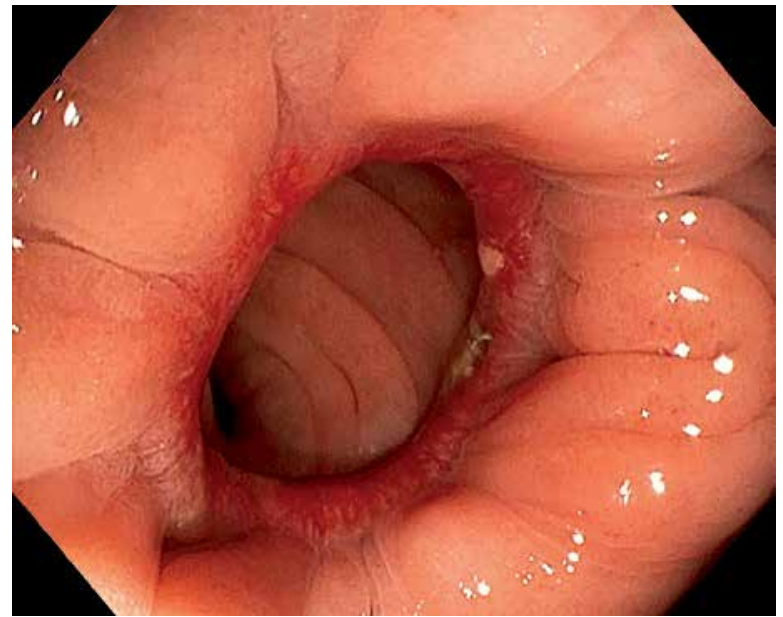

Photo 4. Non-stenosing fibrosis in the anastomosis area

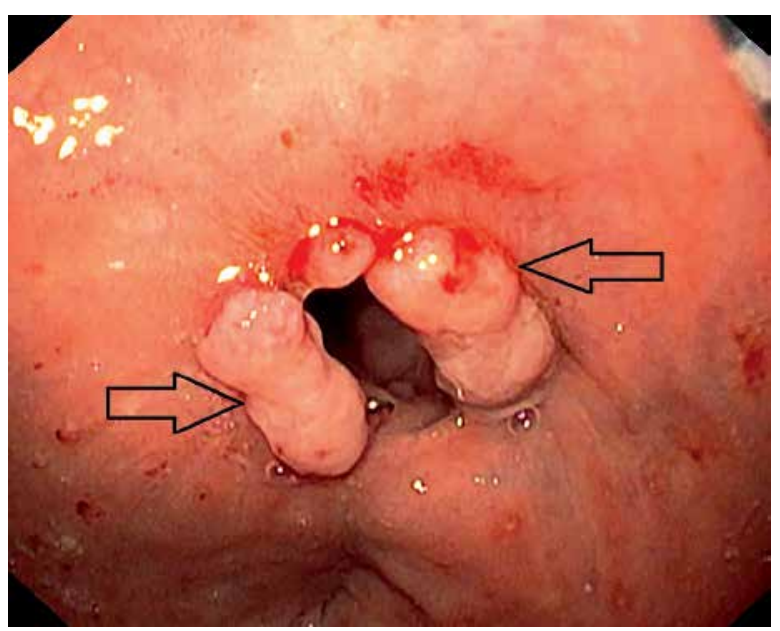

Photo 6. Symptomatic anastomotic stenosis and inflammatory polyps (black arrows). Endoscopy performed 30 days after surgery

pler cartridges used, interruption of mesenteric blood vessels, type and quality of mesorectal excision, circumferential resection margins, and complete histopathology were collected. To assess the incidence of leakage, the patient had to have received at least one endoscopy.

\section{Statistical analysis}

Basic descriptive statistics were used for the analysis: median, mean, and 95\% confidence inter- 
val for continuous data, and absolute and relative frequencies for categorical data. Relationships between anastomosis pathology and other independent factors (age, gender, $\mathrm{T}$ stage, $\mathrm{N}$ stage, tumour and anastomosis location, type/radicality of surgery, type of anastomosis, excision quality, protective ileostomy, neoadjuvant treatment, tumour characteristics, and endoscopic findings) were analysed using the chi-square test, Fisher's exact test, and logistic regression analysis. We considered $p<0.05$ to be statistically significant. All statistical analyses were performed using the NCSS 8 statistical software program (NCSS, Keysville, Utah).

\section{Results}

\section{Surgical procedures}

The tumour was located in the upper rectum in $30(24.2 \%)$ patients, in the middle rectum in 69 (55.6\%) patients, and in the lower rectum in 25 (20.2\%) patients. The mean anastomosis distance from the anal verge was $5.7 \mathrm{~cm}$, and the median was $5 \mathrm{~cm}$ (range: 3-10 cm). Neoadjuvant chemoradiotherapy was indicated in $73(58.8 \%)$ patients, and protective ileostomy was constructed in $81(65.3 \%)$ patients (Table I). The first endoscopic examination was carried out in 123 patients; of those, 114 patients underwent a second endoscopic examination. In 5 patients, there was loss of anastomosis and conversion to Hartmann's procedure, and 5 patients did not undergo further endoscopy. After the endoscopic examination, no complications were observed (Photo 1).

\section{Morbidity and mortality}

Overall, 61 complications were detected in 49 (39.5\%) patients. Of these patients, lack of anastomosis healing was diagnosed in 28 (22.6\%). There was no difference in AL incidence among participating institutions. Most complications, according to the clinical severity (Clavien- Dindo), were Grade 1 and 2 (75.5\%). During the observation period, none of the patients died (Table II).

AL was more common in patients with lower rectal tumours $(32.0 \%, 20.3 \%$, and $20.0 \%$ for lower, middle, and upper rectum, respectively; $p=0.20$ ) and lower localization of anastomosis. AL was significantly higher in male patients $(p=0.04)$, in patients after open surgery $(50.0 \%, 19.4 \%$, and $21.4 \%$ for open surgery, laparoscopy, and robotic surgery, respectively $(p=0.03)$ ), in patients with higher primary tumour (pT) stage $(p=0.014)$, and in patients with lymphangioinvasion $(p=0.006)$ (Table I).

\section{Endoscopic examination}

Prior to patient discharge, acute leaks were diagnosed in 19 of 28 (67.8\%) patients. The first endoscopy revealed 18 of these, and 1 patient underwent urgent surgery following signs of septic shock. Of these, 6 (31.6\%) patients were asymptomatic and 13 (68.4\%) patients were symptomatic.

During the second endoscopy, new AL was diagnosed in 9 of 28 (32.1\%) patients, 4 (44.5\%) of which were asymptomatic and $5(55.5 \%)$ symptomatic. Overall, there were 10 (35.7\%) asymptomatic patients and 18 (64.3\%) symptomatic patients.

Based on clinical severity, 16 of 28 (57.1\%) patients had grade A leakages, 7 (25.0\%) patients had grade B leakages, and 5 patients $(17.9 \%)$ had grade C leakages.

\section{Morphology and localization of dehiscence}

Of the total of 27 endoscopically detected defects in anastomosis, $15(55.2 \%)$ were smaller than $1 / 3$ of the circumference (>12 mm, <12 mm). In 7 (25.9\%) patients the defect affected $1 / 3-1 / 2$ of the circumference, and in the remaining 5 (18.5\%) patients, defects affected more than $1 / 2$ of the circumference. Most defects $(22$ of $27(81 \%))$ were located posteriorly and posterior-laterally. Defects were located ventrally in only 3 patients and laterally in only 2 patients.

\section{Treatment of leakage}

Of the total of 28 leaks, 16 (57.1\%) patients were treated conservatively (parenteral nutrition and antibiotics). Vacuum therapy (B. Braun, Melsungen, Germany) was used in 6 (22.2\%) patients. In 1 patient, an ileostomy was constructed and transanal drainage used. For the remaining 5 (17.8\%) patients, reoperation and conversion to Hartmann's operation was necessary. In 20 of 28 patients, the leak was stabilized or the presacral cavity was reduced with endoscopic signs of healing, i.e., granulation tissue formation was observed. In 2 of 28 patients, the presacral cavity size was enlarged and the treatment strategy was changed to vacuum therapy. As mentioned, 5 patients lost anastomosis and 1 patient developed severe stenosis, which in subsequent follow-up led 
Table I. Patients' characteristics

\begin{tabular}{|c|c|c|c|c|c|}
\hline Parameter & & $\begin{array}{c}\text { Leak } \\
n=28(22.6 \%)\end{array}$ & $\begin{array}{c}\text { Non-leak } \\
n=96(77.4 \%)\end{array}$ & $\begin{array}{c}\text { All } \\
n=124(100 \%)\end{array}$ & Statistics \\
\hline Age & $\begin{array}{c}\text { Median, } \\
\text { mean } \pm \text { standard } \\
\text { deviation }\end{array}$ & $64.55,62.66 \pm 7.80$ & $66.07,64.34 \pm 9.47$ & $65.71,63.96 \pm 9.11$ & $\begin{array}{c}p=0.39 \\
\text { (two sample } \\
\text { t-test assum- } \\
\text { ing equal } \\
\text { variances) }\end{array}$ \\
\hline \multirow[t]{3}{*}{ Gender } & Men & $21(29.2 \%)$ & $51(70.8 \%)$ & $72(100 \%)$ & \\
\hline & Women & 7 (13.5\%) & $45(86.5 \%)$ & 52 (100\%) & \\
\hline & All & 28 & 96 & 124 & $\begin{array}{c}p=0.04 \\
\chi^{2} \text { test }\end{array}$ \\
\hline \multirow[t]{7}{*}{ (y)pT stage } & Tis & $0(0 \%)$ & $2(100 \%)$ & $2(100 \%)$ & \\
\hline & TO & $2(10 \%)$ & $18(90 \%)$ & 20 (100\%) & \\
\hline & $\mathrm{T} 1$ & $1(5.9 \%)$ & $16(94.1 \%)$ & 17 (100\%) & \\
\hline & $\mathrm{T} 2$ & $6(16.7 \%)$ & $30(83.3 \%)$ & $36(100 \%)$ & \\
\hline & $\mathrm{T} 3$ & $18(40.9 \%)$ & $26(59.1 \%)$ & 44 (100\%) & \\
\hline & $\mathrm{T} 4$ & $1(33.3 \%)$ & $2(66.7 \%)$ & $3(100 \%)$ & \\
\hline & All & 28 & 94 & 122 & $\begin{array}{c}p=0.014 \\
\chi^{2} \text { test }\end{array}$ \\
\hline \multirow[t]{4}{*}{ (y)pN stadium } & NO & 19 (21.6\%) & $69(78.4 \%)$ & 88 (100\%) & \\
\hline & N1 & $8(29.6 \%)$ & $19(70.4 \%)$ & 27 (100\%) & \\
\hline & N2 & $1(11.1 \%)$ & $8(88.9 \%)$ & 9 (100\%) & \\
\hline & All & 28 & 96 & 124 & $\begin{array}{c}p=0.47 \\
\chi^{2} \text { test }\end{array}$ \\
\hline \multirow[t]{3}{*}{ (y)pM } & MO & $28(23.5 \%)$ & $91(76.5 \%)$ & 119 (100\%) & \\
\hline & M1 & $0(0.0 \%)$ & $5(100 \%)$ & $5(100 \%)$ & \\
\hline & All & 28 & 96 & 124 & $\begin{array}{c}p=0.22 \\
\chi^{2} \text { test }\end{array}$ \\
\hline \multirow[t]{4}{*}{ Tumour location } & Upper rectum & $6(20 \%)$ & $24(80 \%)$ & $30(100 \%)$ & \\
\hline & Mid rectum & $14(20.3 \%)$ & $55(79.7 \%)$ & 69 (100\%) & \\
\hline & Distal rectum & $8(32.0 \%)$ & $17(68.0 \%)$ & $25(100 \%)$ & \\
\hline & All & 28 & 96 & 124 & $\begin{array}{c}p=0.45 \\
\chi^{2} \text { test }\end{array}$ \\
\hline \multirow{4}{*}{$\begin{array}{l}\text { Anastomosis } \\
\text { level }\end{array}$} & $<5 \mathrm{~cm}$ & $12(27.9 \%)$ & $31(72.1 \%)$ & $43(100 \%)$ & \\
\hline & $<10 \mathrm{~cm}$ & $15(22.4 \%)$ & $52(77.6 \%)$ & $67(100 \%)$ & \\
\hline & $<15 \mathrm{~cm}$ & $1(14.3 \%)$ & $6(85.7 \%)$ & 7 (100\%) & \\
\hline & All & 28 & 89 & 117 & $\begin{array}{c}p=0.66 \\
\chi^{2} \text { test }\end{array}$ \\
\hline \multirow{6}{*}{$\begin{array}{l}\text { Surgical } \\
\text { approach }\end{array}$} & Open & $5(50 \%)$ & $5(50 \%)$ & $10(100 \%)$ & \\
\hline & Lap & $14(19.4 \%)$ & $58(80.6 \%)$ & $72(100 \%)$ & \\
\hline & Robotic & $9(21.4 \%)$ & $33(78.6 \%)$ & 42 (100\%) & \\
\hline & TA-TME & 0 & 0 & 0 & \\
\hline & Jiné & 0 & 0 & 0 & \\
\hline & All & 28 & 96 & 124 & $\begin{array}{c}p=0.09 \\
\chi^{2} \text { test }\end{array}$ \\
\hline
\end{tabular}


Table I. Cont.

\begin{tabular}{|c|c|c|c|c|c|}
\hline Parameter & & $\begin{array}{c}\text { Leak } \\
n=28(22.6 \%)\end{array}$ & $\begin{array}{c}\text { Non-leak } \\
n=96(77.4 \%)\end{array}$ & $\begin{array}{c}\text { All } \\
n=124(100 \%)\end{array}$ & Statistics \\
\hline \multirow{3}{*}{$\begin{array}{l}\text { Type of anasto- } \\
\text { mosis }\end{array}$} & Monostapler & $6(27.3 \%)$ & $16(72.7 \%)$ & $22(100 \%)$ & \\
\hline & Bi-stapler & $19(20.9 \%)$ & $72(79.1 \%)$ & $91(100 \%)$ & \\
\hline & All & 25 & 88 & 113 & $\begin{array}{c}p=0.51 \\
\chi^{2} \text { test }\end{array}$ \\
\hline \multirow{6}{*}{$\begin{array}{l}\text { Stapler diameter } \\
{[\mathrm{mm}]}\end{array}$} & 25 & $3(30 \%)$ & $7(70 \%)$ & $10(100 \%)$ & \\
\hline & 28 & $1(11.1 \%)$ & $8(88.9 \%)$ & $9(100 \%)$ & \\
\hline & 29 & $9(18.4 \%)$ & $40(81.6 \%)$ & 49 (100\%) & \\
\hline & 31 & $6(31.6 \%)$ & $13(68.4 \%)$ & $19(100 \%)$ & \\
\hline & 33 & $6(23.1 \%)$ & $20(76.9 \%)$ & $26(100 \%)$ & \\
\hline & All & 25 & 88 & 113 & $\begin{array}{c}p=0.66 \\
\chi^{2} \text { test }\end{array}$ \\
\hline \multirow[t]{4}{*}{ Vessel dissection } & $\begin{array}{l}\text { Inferior } \\
\text { mesenteric } \\
\text { artery }\end{array}$ & $10(20.8 \%)$ & 38 (79.2\%) & 48 (100\%) & \\
\hline & $\begin{array}{c}\text { Superior rectal } \\
\text { artery }\end{array}$ & $16(31.4 \%)$ & $35(68.6 \%)$ & $51(100 \%)$ & \\
\hline & Left colic artery & $2(8 \%)$ & $23(92 \%)$ & 25 (100\%) & \\
\hline & All & 28 & 96 & 124 & $\begin{array}{c}p=0.07 \\
\chi^{2} \text { test }\end{array}$ \\
\hline \multirow[t]{5}{*}{ Stapler cartridges } & 1 & $4(23.5 \%)$ & $13(76.5 \%)$ & 17 (100\%) & \\
\hline & 2 & $12(17.9 \%)$ & $55(82.1 \%)$ & 67 (100\%) & \\
\hline & 3 & $9(31.0 \%)$ & $20(69.0 \%)$ & $29(100 \%)$ & \\
\hline & $>3$ & 0 & 0 & 0 & \\
\hline & All & 25 & 88 & 113 & $\begin{array}{c}p=0.36 \\
\chi^{2} \text { test }\end{array}$ \\
\hline \multirow[t]{3}{*}{ Ileostomy } & Yes & $21(25.9 \%)$ & $60(74.1 \%)$ & $81(100 \%)$ & \\
\hline & No & $7(16.3 \%)$ & $36(83.7 \%)$ & $43(100 \%)$ & \\
\hline & All & 28 & 96 & 124 & $\begin{array}{c}p=0.22 \\
\chi^{2} \text { test }\end{array}$ \\
\hline \multirow[t]{4}{*}{ Excision quality } & Mesorectal & $11(15.7 \%)$ & $59(84.3 \%)$ & 70 (100\%) & \\
\hline & Intramesorectal & $13(40.6 \%)$ & 19 (59.4\%) & $32(100 \%)$ & \\
\hline & Muscular & $3(16.7 \%)$ & 15 (83.3\%) & 18 (100\%) & \\
\hline & All & 27 & 93 & 120 & $\begin{array}{c}p=0.016 \\
\chi^{2} \text { test }\end{array}$ \\
\hline \multirow{4}{*}{$\begin{array}{l}\text { Resection } \\
\text { margins }\end{array}$} & RO & 24 (22.0\%) & 85 (78.0\%) & 109 (100\%) & \\
\hline & R1 & $1(10 \%)$ & 9 (90\%) & 10 (100\%) & \\
\hline & R2 & 2 (100\%) & $0(0 \%)$ & 2 (100\%) & \\
\hline & All & 27 & 94 & 121 & $\begin{array}{c}p=0.02 \\
\chi^{2} \text { test }\end{array}$ \\
\hline \multirow[t]{3}{*}{ pCRM } & pCRM neg & $26(25 \%)$ & 78 (75\%) & 104 (100\%) & \\
\hline & pCRM poz & $2(28.6 \%)$ & $5(71.4 \%)$ & 7 (100\%) & \\
\hline & All & 28 & 83 & 111 (100\%) & $\begin{array}{c}p=0.83 \\
\chi^{2} \text { test }\end{array}$ \\
\hline
\end{tabular}


Table I. Cont.

\begin{tabular}{|c|c|c|c|c|c|}
\hline Parameter & & $\begin{array}{c}\text { Leak } \\
n=28(22.6 \%)\end{array}$ & $\begin{array}{c}\text { Non-leak } \\
n=96(77.4 \%)\end{array}$ & $\begin{array}{c}\text { All } \\
n=124(100 \%)\end{array}$ & Statistics \\
\hline \multirow[t]{3}{*}{ Neoadjuvant RT } & No & $8(15.7 \%)$ & 43 (84.3\%) & $51(100 \%)$ & \\
\hline & Yes & $20(27.4 \%)$ & $53(72.6 \%)$ & 73 (100\%) & \\
\hline & Celkem & 28 & 96 & 124 & $\begin{array}{c}p=0.12 \\
\chi^{2} \text { test }\end{array}$ \\
\hline \multirow{3}{*}{$\begin{array}{l}\text { Lymphangio- } \\
\text { invasion }\end{array}$} & No & 21 (19.8\%) & 85 (80.2\%) & $106(100 \%)$ & \\
\hline & Yes & $7(53.8 \%)$ & $6(46.2 \%)$ & $13(100 \%)$ & \\
\hline & All & 28 & 91 & 119 & $\begin{array}{c}p=0.006 \\
\chi^{2} \text { test }\end{array}$ \\
\hline \multirow[t]{3}{*}{ Angioinvasion } & No & 21 (20.4\%) & $82(79.6 \%)$ & $103(100 \%)$ & \\
\hline & Yes & $7(41.2 \%)$ & 10 (58.8\%) & 17 (100\%) & \\
\hline & All & 28 & 92 & 120 & $\begin{array}{c}p=0.06 \\
\chi^{2} \text { test }\end{array}$ \\
\hline
\end{tabular}

to re-resection and loss of anastomosis. The loss of anastomosis was associated with endoscopic signs of transmural intestinal ischemia in all patients.

\section{Photographic documentation evaluation}

Only good quality photographs were evaluated.

\section{Other pathological findings in the anastomosis patients $(n=82)$}

Only 19 of 82 (23.1\%) patients had a normal anastomosis finding (Photo 1 ). The remaining 35 (42.6\%) patients had a pathological finding other than leakage (inflammation, inflammatory polyps, ulcer, non-stenotic fibrosis, and stenosis). There were differences between patients with and without preoperative radiotherapy, with patients without radiation therapy having more non-stenotic fibrosis, stenosis, and inflammatory polyps.

\section{Endoscopic signs of intestinal ischaemia, evaluated patients $(n=82)$}

Signs of intestinal ischaemia were found in $5 \mathrm{pa}$ tients. Four patients had transmural ischaemia, which was confirmed intraoperatively during the revision. Anastomotic stenosis developed in 1 patient with a non-circular ischaemia.

\section{Endoscopic signs of anastomosis tension, evaluated patients $(n=82)$}

Straightening of the colon above the anastomosis, the so-called "chimney sign", was considered
Table II. Postoperative complications

\begin{tabular}{|c|c|c|}
\hline Variability & $N=124$ & $\%$ \\
\hline Mortality & 0 & 0 \\
\hline Morbidity & 49 & 39.5 \\
\hline Dindo-Clavien & $N=49$ & $\%$ \\
\hline Dindo 1 & 14 & 28.6 \\
\hline Dindo 2 & 23 & 46.9 \\
\hline Dindo 3 & 11 & 22,4 \\
\hline Dindo 4 & 1 & 2 \\
\hline Dindo 5 & 0 & 0 \\
\hline Specific complications & $N=61$ & $\%$ \\
\hline Leak: & 28 & 22.5 \\
\hline Asymptomatic & 11 & \\
\hline Symptomatic & 17 & \\
\hline Wound complications: & 16 & 12.9 \\
\hline Superficial & 14 & \\
\hline Deep & 2 & \\
\hline Others: & 17 & 13.7 \\
\hline Postoperative bleeding & 1 & \\
\hline Postoperative ileus & 2 & \\
\hline Dehydration & 5 & \\
\hline Urinary infection & 1 & \\
\hline Gl bleeding & 2 & \\
\hline Urinary retention & 2 & \\
\hline Sepsis & 1 & \\
\hline Recto-vesical fistula & 1 & \\
\hline Delirium & 1 & \\
\hline Skin efflorescences & 1 & \\
\hline
\end{tabular}


an endoscopic sign of anastomosis tension and was seen on imaging in 15 (18.3\%) of 82 patients. In most cases, this finding was associated with a pathological finding of anastomotic leak in 4 patients, stenosis or fibrosis in 4 patients, and anastomosis ulcer in 4 patients. Normal findings were seen in the remaining 3 patients.

\section{Endoscopic signs of released stapler clamps, evaluated patients $(n=98)$}

Detection of released staples was noted in 62 of 98 (63.2\%) patients versus 36 (36.7\%) patients. No statistically significant relationship between staple release and age, sex, pT stage, surgical approach, anastomosis type, or stapler diameter was proven. Significantly more released staples were found in patients with protective ileostomy $(p=0.03)$, and more released staples were found in low anastomoses up to $5 \mathrm{~cm}(66.7 \%$ vs. $33.3 \%)$.

\section{Discussion}

Our study results confirmed the suspicion that not only leaks but also other anastomotic pathologies are more frequent than was expected. $A L$ is a complication that is difficult to predict and can occur even when the surgeon is convinced that all measures have been undertaken to prevent it. Efforts to identify preoperative or perioperative risk factors for $A L$ and attempts to develop a predictive scoring system [8, 9] have not yet been successful. Therefore, colorectal $\mathrm{AL}$ is the subject of continuing discussions in the surgical community [10]. Several surgeons perceive some discrepancy between what is claimed at scientific and medical congresses and what is seen in clinical practice. Researchers have reported values that range from $1 \%$ to $28 \%$ [10-20]. Cong et al. [4] performed a systematic analysis of available published data and found differences between Asian countries, where the average leakage rate was $5.43 \%$, and European countries, where this number was as high as $11.09 \%$. In Europe, there are notable differences between countries, e.g., France $17.46 \%$, Belgium $6.67 \%$, and Ireland $4.0 \%$, and it has been suggested that this is also because of the quality of the registers [11] and the quality of the data collection. However, it is clear that grade A leakages are rarely reported [4]. Borstlap et al., in 2017, analysed data from the Dutch Surgical Colorectal Audit; anastomotic leakage was diagnosed in $13.4 \%$ of patients within 30 days, which increased to $20 \%$ beyond 30 days, and nonhealing leak at 12 months was observed in $48 \%$ of patients [21].

Probably the most important factor associated with leak occurrence is surgeon experience. Experienced surgeons had a leak rate of around $5 \%$. An interesting question is how many patients are diverted. This factor may influence not only surgeon expertise but also patient selection.

Results showed that the incidence of leakage was significantly higher in males. Furthermore, these patients had higher stages of pT tumour, non-radical surgical procedures, and worse quality of mesorectal excisions.

An interesting and statistically significant factor associated with the occurrence of $\mathrm{AL}$ was lymphangioinvasion (Table I). Stapler diameter, number of used cartridges, and type of vessel dissection were not associated with leakage or stenosis. Most anastomotic defects were found to be localized posteriorly or posterior-laterally (81\%). The reason behind this is unclear. A higher posterior stretch or tears in crossing stapler lines in bistapler technique are possible reasons, but this has not been addressed.

The group of patients with leakages is not large, so our results do not have enough statistical power to identify risk factors associated with leak, as in other published studies [22, 23]. However, endoscopy revealed other anastomotic pathologies which can be associated with poor postoperative functional results such as bowel dysfunction and urgency. Future research into the relationships between different anastomotic pathologies, including ulcer, polyps, and fibrosis, and patient postoperative dysfunctions, is required.

Early detection, which is based on a proactive approach, especially between 2-5 postoperative days, is essential in the treatment of colorectal anastomosis dehiscence. Monitoring CRP levels is an important supplemental tool [7], but clinical observation is essential. Knowledge of the morphology and magnitude of disruption of the anastomosis circumference, vitality and colon retraction, and the presence of the perianastomotic cavity are important in determining further treatment strategy. The elimination of pelvic sepsis is a priority, and vacuum therapy seems to be an effective tool in patients without diffuse peritonitis [21]. It is not advisable to treat the dehiscence of most of the anastomotic circumference with a large presacral cavity. This sit- 
uation will likely result in colon stenosis and small pelvic fibrotization, and further surgery will be technically demanding with a dubious functional result. In comparison to posterior leaks, ventral leaks will likely heal better. Guel-Klein et al. published a grading system in 2019 based on 50\% circumference necrosis and abscess cavity presence [24]. Our experience showed that even a small leak entry would have a large abscess cavity behind. The possibility of flexible endoscope introduction into the cavity is important, so the cut-off value for leak entry was predetermined as $12 \mathrm{~mm}$ [25]. Colonic wall retraction is another important factor, when transanal leak repair is considered. A more detailed morphology-prognostic leak classification is needed [3].

The literature on early postoperative endoscopy in $\mathrm{AL}$ diagnosis is sparse. Ikeda published a retrospective analysis of 41 patients, but endoscopy was performed only in symptomatic patients [26].

Our initial experience has shown that endoscopy allows for the rapid diagnosis of anastomotic pathologies and consequent prompt interventions. In addition, endoscopic examination revealed leakages in anastomoses that were clinically silent. This patient subgroup requires more detailed research. Our own experience and the published literature suggest that not all asymptomatic leaks will be healed and allow stoma closure [27].

\section{Conclusions}

Patients with elevated CRP levels would benefit from this proactive approach. In a group of patients with leakages, unlike other diagnostic methods, such as contrast enema and computed tomography (CT) of the pelvis, endoscopy provides important information about morphology and localization of the defect, the condition of the colonic wall, their vitality and retraction, and the presence of pus and necroses in the adjacent cavity, all of which are important factors for further treatment.

In addition, early postoperative endoscopy revealed another quite large group of patients with clinically silent AL. Endoscopy would enable treatment to begin earlier and, consequently, improve patient outcomes.

\section{Acknowledgments}

This research was supported by the Ministry of Health Care, Czech Republic, MH CZ - DRO (FNHK,
00179906) and by the Ministry of Health of the Slovak Republic under the project registration number 2018/16-UKMT-12.

\section{Conflict of interest}

The authors declare no conflict of interest.

\section{References}

1. Hain E, Maggiori L, Manceau C, et al. Oncological impact of anastomotic leakage after laparoscopic mesorectal excision. Br J Surg 2017; 104: 288-95.

2. McDermott FD, Heeney A, Kelly ME, et al. Systematic review of preoperative, intraoperative and postoperative risk factors for colorectal anastomotic leaks. Br J Surg 2015; 102: 462-79.

3. Rahbari NN, Weitz J, Hohenberger W, et al. Definition and grading of anastomotic leakage following anterior resection of the rectum: a proposal by the International Study Group of Rectal Cancer. Surgery 2010; 147: 339-51.

4. Cong ZJ, Hu LH, Bian ZQ, et al. Systematic review of anastomotic leakage rate according to an international grading system following anterior resection for rectal cancer. PLoS One 2013; 8: e75519.

5. Nesbakken A, Nygaard K, Lunde OC, et al. Anastomotic leak following mesorectal excision for rectal cancer: true incidence and diagnostic challenges. Colorectal Dis 2005; 7: 576-81.

6. Huiberts AA, Dijksman LM, Boer SA, et al. Contrast medium at the site of the anastomosis is crucial in detecting anastomotic leakage with CT imaging after colorectal surgery. Int I Colorectal Dis 2015; 30: 843-8.

7. Rink AD, Kienle P, Aigner F, et al. How to reduce anastomotic leakage in colorectal surgery-report from German expert meeting. Langenbecks Arch Surg 2020 doi: 10.1007/s00423-02001864-5. [Epub ahead of print] 2020

8. Kornmann VN, van Ramshorst B, Smits AB, et al. Beware of false-negative CT scan for anastomotic leakage after colonic surgery. Int J Colorectal Dis 2014; 29: 445-51.

9. Dekker JW, Liefers GJ, de Mol van Otterloo JC, et al. Predicting the risk of anastomotic leakage in left-sided colorectal surgery using a colon leakage score. J Surg Res 2011; 166: 27-34.

10. Rojas-Machado SA, Romero-Simó M, Arroyo A, et al. Prediction of anastomotic leak in colorectal cancer surgery based on a new prognostic index PROCOLE (prognostic colorectal leakage) developed from the meta-analysis of observational studies of risk factors. Int J Colorectal Dis 2016; 31: 197-210.

11. Vallance A, Wexner S, Berho M, et al. A collaborative review of the current concepts and challenges of anastomotic leaks in colorectal surgery. Colorectal Dis 2017; 19: 01-12.

12. Borly L, Ellebæk MB, Qvist N. Leakage after surgery for rectum cancer: inconsistency in reporting to the Danish Colorectal Cancer Group. Surg Res Pract 2015; 2015: 376540.

13. Bakker N, Deelder JD, Richir MC, et al. Risk of anastomotic leakage with nonsteroidal anti-inflammatory drugs within an enhanced recovery program. J Gastrointest Surg 2016; 20: 776-82.

14. Tanaka J, Nishikawa T, Tanaka T, et al. Analysis of anastomotic leakage after rectal surgery: a case-control study. Ann Med Surg 2015; 4: 183-6. 
15. Karliczek A, Harlaar NJ, Zeebregts CJ, et al. Surgeons lack predictive accuracy for anastomotic leakage in gastrointestinal surgery. Int J Colorectal Dis 2009; 24: 569-76.

16. Matsuda K, Hotta T, Takifuji K, et al. Clinical characteristics of anastomotic leakage after an anterior resection for rectal cancer by assessing of the international classification on anastomotic leakage. Langenbecks Arch Surg 2015; 400: 207-12.

17. Wang S, Zhang Z, Liu M, et al. Efficacy of transanal tube placement after anterior resection for rectal cancer: a systematic review and meta-analysis. World J Surg Oncol 2016; 14: 92.

18. Shigeta K, Okabayashi K, Baba H, et al. A meta-analysis of the use of a transanal drainage tube to prevent anastomotic leakage after anterior resection by double-stapling technique for rectal cancer. Surg Endosc 2016; 30: 543-50.

19. Caulfield H, Hyman NH. Anastomotic leak after low anterior resection: a spectrum of clinical entities. JAMA Surg 2013; 148 177-82.

20. $\mathrm{Hu} \mathrm{X}$, Cheng YA. Clinical parameters-based model predicts anastomotic leakage after a laparoscopic total mesorectal excision: a large study with data from China. Medicine (Baltimore) 2015; 94: e1003.

21. Borstlap WAA, Westerduin E, Aukena TS, et al. Anastomotic leak and chronic presacral sinus formation after low anterior resection. Results from a large cross-sectional study. Ann Surg 2017; 266: 870-7.

22. Espín E, Ciga MA, Pera M, et al. Oncological outcome following anastomotic leak in rectal surgery. Br J Surg 2015; 102: 416-22.

23. Pommergaard HC, Gessler B, Burcharth J, et al. Preoperative risk factor for anastomotic leakage after resection for colorectal cancer: a systematic review and meta-analysis. Colorecta Disease 2014; 16: 662-71.

24. Guel-Klein E, Biebl M, Knoll B, et al. Anastomotic leak after transanal total mesorectal excision: grading of severity and management aimed at preservation of the anastomosis. Colorectal Disease 2019; 21: 894-902.

25. Yang SY, Han J, Han YD, et al. Intraoperative colonoscopy for the assessment and prevention of anastomotic leakage in low anterior resection for rectal cancer. Int J Colorectal Dis 2017; 32: 709-14.

26. Ikeda T, Kumashiro R, Oki E, et al. Evaluation of techniques to prevent colorectal anastomotic leakage. J Surg Res 2015; 194: 450-7.

27. Hain E, Maggiori L, Manceau G, et al. Persistent asymptomatic anastomotic leakage after laparoscopic sphincter-saving surgery for rectal cancer: can diverting stoma be reversed safely at 6 months? Dis Colon Rectum 2016; 59: 369-76.

Received: 6.04.2020, accepted: 4.06.2020. 